\title{
COVID-19, ANÁLISE DAS ESTRATÉGIAS DE PREVENÇÃO, CUIDADOS E COMPLICAÇÕES SINTOMÁTICAS
}

COVID-19, analysis of prevention strategies, care and symptomatic complications

COVID-19, análisis de las estrategias de prevención, cuidados y complicaciones sintomáticas

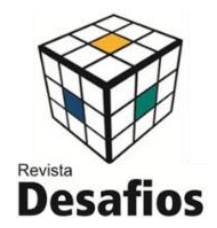

\section{Anderson Barbosa Baptista*1, Leonardo Vieira Fernandes ${ }^{2}$,}

${ }^{1}$ Laboratório de Microbiologia, Curso de Medicina, Universidade Federal do Tocantins, Palmas, Brasil.

${ }^{2}$ Saúde e Atenção à Comunidade, Curso de Medicina, Universidade Federal de Catalão, Catalão, Brasil.

*Correspondência: Laboratório de Microbiologia, Prédio do Mestrado em Ciências da Saúde, Curso de Medicina, Av. NS 15, 109 Norte, Palmas, Tocantins, Brasil.CEP:77.010-090.e-mail biomeddu@yahoo.com.br.

Artigo recebido em 03/04/2020 aprovado em 21/04/2020 publicado em 22/04/2020.

\section{RESUMO}

O vírus SARS-CoV-2 surgiu no final de 2019 em Wuhan, na China, provocando a COVID-19, sendo decretada uma pandemia em março de 2020. Possui alta transmissibilidade, podendo produzir complicações sintomáticas. Medidas de isolamento social e antissepsia são elementos chave para contenção do vírus. Objetivou-se nesse estudo uma revisão da literatura referente à COVID-19 e sua relação com pneumonia, sua prevenção e impactos na saúde pública. Foi realizada busca nas bases de dados PubMed, Bireme, Scielo, Portal da Capes e revistas especializadas. Novas doenças geram muitos desafios pela imprecisão de conhecimentos. O paciente com COVID-19 pode apresentar sintomas como: tosse seca, febre, dor de garganta, dor no corpo e complicações como: pneumonia, dispneia e necessidade de ventilação mecânica. O diagnóstico é realizado por meio de sorologia e/ou RT-PCR. Para diminuir a transmissão do vírus as estratégias estão centradas em medidas como antissepsia das mãos, do ambiente e no isolamento social. No Brasil, o sistema de saúde não comporta um rápido aumento do número de casos. É o momento de divulgação de conhecimento em saúde para a população, para que a pandemia que chega ao país seja mitigada. Há necessidade de estruturação do sistema de saúde para o enfrentamento de desastres.

Palavras-chave: COVID-19; Antissepsia; Isolamento social.

\section{ABSTRACT}

SARS-CoV-2 virus, emerged in late 2019 in Wuhan, China, causing the COVID-19 pandemic was decreed in March 2020. It is highly transmissible and can produce symptomatic complications. Social isolation and antisepsis measures are key elements in containing the virus. The aim of this study was to review the literature regarding COVID-19 and its relationship with pneumonia, prevention and impacts on public health. A search was performed in the PubMed, Bireme, Scielo, Capes and specialized magazines databases. New diseases generate many challenges due to inaccuracy of knowledge. The patient with COVID-19 may present symptoms such as: dry cough, fever, sore throat, body pain and complications such as pneumonia, dyspnea and the need for mechanical ventilation. The diagnosis is made by serology and / or RT-PCR. To reduce the transmission of the virus, strategies are centered on measures such as antisepsis of the hands, the environment and social isolation. In Brazil, the health system would not support a rapid increase in the number of cases. It is the time of the dissemination of health knowledge to the population, so that the pandemic that reaches the country is mitigated. It is also evident the need to structure the health system to face disasters.

Keywords: COVID-19; antisepsis; Social isolation. 


\section{RESUMEN}

El virus SARS-CoV-2 apareció al final de 2019 en Wuhan, China, causando COVID-19, y se declaró una pandemia en marzo de 2020. Tiene una alta transmisibilidad y puede producir complicaciones sintomáticas. Las medidas de aislamiento social y antisepsia son elementos clave para contener el virus. El objetivo de este estudio fue revisar la literatura sobre COVID-19 y su relación con la neumonía, su prevención e impactos en la salud pública. Se realizó una búsqueda en PubMed, Bireme, Scielo, Portal de Capes y bases de datos de revistas especializadas. Las nuevas enfermedades generan muchos desafios debido a la falta de conocimiento. El paciente con COVID-19 puede presentar síntomas como: tos seca, fiebre, dolor de garganta, dolor corporal y complicaciones como neumonía, disnea y la necesidad de ventilación mecánica. El diagnóstico se realiza por serología y/o RT-PCR. Para reducir la transmisión del virus, las estrategias se centran en medidas como la antisepsia de las manos, el medio ambiente y el aislamiento social. En Brasil, el sistema de salud no admite un rápido aumento en el número de casos. Muchas muertes podrían ocurrir sin medidas de aislamiento y prevención. Es el momento de difusión del conocimiento de la salud a la población, para mitigar la pandemia que llega al país. Hay necesidad de estructurar el sistema de salud para enfrentar los desastres.

Descriptores: COVID-19; antisepsia; aislamiento social.

\section{INTRODUÇÃO}

Desde a década de 1970 as patologias contagiosas como Herpes, AIDS, Ebola, Síndrome Respiratória Aguda Grave (SARS), Síndrome Respiratória do Oriente Médio (MERS-COV) e atualmente a Doença por Coronavírus 2019 (COVID19) são doenças que perturbam e impactam a população. As situações de emergência em saúde já foram vistas anteriormente e a COVID-19 não é diferente (VALENTIN et al., 2019; ARSHAD et al., 2020; JONES, 2020). Em meio à progressão galopante do número de casos e mortes de uma doença emergente, às medidas radicais de distanciamento social e quarentena, e às inúmeras questões ainda desconhecidas da história natural da doença, uma das perguntas instigantes é se a quarentena poderia falhar pela condição de pessoas se tornarem transmissores assintomáticos. É importante que esteja claro que as intervenções das Instituições e Governos não são fúteis, pois contribuem na diminuição do curso da epidemia e das mortes, e proporciona correções de medidas equivocadas (JONES, 2020).

Os Coronaviridae são vírus de RNA de fita positiva envelopados, de distribuição mundial, associados ao resfriado comum; foram nomeados "coronavírus" por causa das grandes moléculas de proteína de espiga na sua superfície que dão aos virions a forma de coroa (BLACK, 2002). O coronavírus relacionado à síndrome respiratória aguda grave (SARS-CoV) infecta uma ampla variedade de espécies animais, incluindo seres humanos, macacos, gatos domésticos, furões, hamsters, cães, guaxinim e morcegos; acredita-se que os morcegos abriguem os precursores do SARS-CoV e, portanto, sejam o reservatório natural do vírus (VICENZI et al., 2004; LI 2013). Nos humanos está associado a endemias e epidemias, e pode provocar casos graves de problemas respiratórios como Síndrome da Angústia Respiratória (SARA) (KASMI et al., 2020).

Um novo tipo de coronavírus, denominado Coronavírus 2 da Síndrome Respiratória Aguda Severa, SARS-CoV-2, responsável pela atual pandemia decretada em 11 de março último pela Organização Mundial de Saúde (WHO a, 2020), surgiu na cidade de Wuhan na China no final de 2019 e se espalhou rapidamente para todas as províncias chinesas, e, em 1 de março de 2020, estava em 58 outros países. Muitos esforços para conter o vírus estão 
em andamento como medidas de antissepsia das mãos, isolamento social e atenção especial com os idosos (LI et al., 2020). A China já foi epicentro de outra pandemia no passado: a SARS, que surgiu no sul do país em 2002 e se espalhou pelo mundo (LI, 2013).

Casos graves da COVID-19 têm sido associados a doenças crônicas como cardiovasculares, principalmente hipertensão, diabetes, neoplasias e doenças respiratórias (CHEN, 2020). A transmissão da COVID-19 se dá por gotículas em tosse, espirros, fluídos e, provavelmente, superfícies de qualquer tipo, sendo altamente contagioso (CABRERA et al., 2020).

Objetivou-se a revisão de artigos atualizados, que se referem a infecções provocadas pela COVID19 e a relação com complicações sintomáticas, comorbidades, prevenção e impactos na saúde pública.

\section{MATERIAIS E MÉTODOS}

Análise da literatura referentes à COVID-19 associadas as infecções respiratórias, especialmente à pneumonia, antissepsia e prevenção. Foram utilizadas as bases PubMed, Scielo, Portal da Capes e Bireme. Sites/ revistas especializados em COVID-19: The New England Journal of Medicine, The BMJ/coronavirus, JAMA Network. Utilizaram-se descritores como “COVID-19”, "pneumonias", “antissepsia”, "assepsia", "isolamento social", "comorbidades", “impactos sistema de saúde”, “coronavírus".

\section{RESULTADOS E DISCUSSÃO}

Infecções do trato respiratório inferior, como as pneumonias, podem ser causadas por agentes virais, dos quais os mais envolvidos incluem: o vírus respiratório sincicial ( $\mathrm{RSV}$ ), influenza $\mathrm{A} / \mathrm{B}$, rinovírus, adenovírus, vírus Eppstein-Barr (EBV) e citomegalovírus (CMV); bactérias mais comuns como Streptococcus pneumoniae, Haemophilus influenzae, Mycoplasma pneumoniae, Chlamydophila pneumoniae e Legionella pneumophila (Unver et al., 2018) e, atualmente, em emergência de saúde mundial, o coronavírus (SARS-CoV-2) (NG OT et al., 2020). Não há estudos controlados avaliando o uso de antimicrobianos empíricos em COVID-19. Dados de superinfecção bacteriana são escassos, e um estudo de grande número de pacientes em Wuhan, os serviços médicos mostraram-se muito sobrecarregados para se obter amostras de alta qualidade (GUAN et al., 2020). A Society of Critical Care Medicine and the European Society of Intensive Care Medicine recomendam /sugerem a utilização empírica de agentes antibacterianos/microbianos, considerando uma recomendação com baixo nível de evidência e embasada na extrapolação de dados deste estudo de outras pneumonias virais, especialmente influenza (ALHAZZANI, 2020).

Quando doenças novas aparecem há muitos desafios, assim como ocorreu com a influenza A (H1N1), doença pandêmica que sobrecarregou o sistema público, vinda inicialmente do porco, com alto índice de letalidade. A transmissão ocorre principalmente por meio das mãos e gotículas contaminadas e causa casos graves de pneumonia (NICOLINI et al., 2011). A COVID-19 pode ser sintomática com o paciente apresentando tosse seca, febre, dor de garganta, evolução para pneumonia com necessidade de ventilação mecânica revelando opacificação bilateral do espaço aéreo ou simplesmente ser assintomático, podendo apresentar apenas uma neutropenia leve e diarreia (NG OT et al., 2020).

Segundo recomendações da Sociedade Brasileira de Pneumologia e Tisiologia a Tomografia Computadorizada não deve ser usada na triagem de COVID-19 em pacientes assintomáticos, devendo ser considerada em pacientes hospitalizados, apenas em sintomáticos ou em situações clínicas específicas. 
Considera ainda que os achados tomográficos da pneumonia por COVID-19 são inespecíficos, semelhantes aos de outras infecções pulmonares, de acordo com a fase da doença (ARAÚJO-FILHO, 2020). Achados na radiografia simples de tórax, são menos significativos e espelham os descritos em TC com consolidações periféricas basais bilaterais e/ou opacidade em vidro fosco, com pico 10-12 dias do início dos sintomas (WONG, 2020).

O padrão ouro para diagnóstico laboratorial da COVID-19 é a reação da transcriptase reversa, seguida de reação em cadeia da polimerase (RT-PCR) para amostras do trato respiratório (ECEMIS et al.,2013; LAN et al., 2020). O exame de PCR para a COVID-19 utiliza a extração do RNA viral com kit EZ1 (Qiagen), utilizando dois métodos específicos de RT-PCR em tempo real direcionados ao $\mathrm{N}$ e ORF1ab; foram projetados para detectar a presença de SARS-CoV-2 em amostras clínicas. (NG OT et al., 2020). Outro método, mais rápido, é o teste sorológico em sangue total, soro ou plasma a depender do kit de reagentes, que detecta anticorpos $\operatorname{IgM}$ e $\operatorname{IgG}$, que pode ser utilizado em pacientes com poucos sintomas ou assintomático (SBAC, 2020).

De 1 a 20 de janeiro de 2020, Chen et al (2020), analisaram casos suspeitos de COVID-19, no hospital de Wuhan. A RT-PCR foi utilizada para o diagnóstico do vírus em amostras de $S w a b$ de orofaringe. $\mathrm{O}$ aspirado traqueal foi utilizado para verificar infecções provocadas por bactérias e fungos. Todos os pacientes fizeram RX de tórax e Tomografia Computadorizada. Dos 99 casos positivos, a maioria apresentou tosse e febre e um terço falta de ar; $8 \%$ com lesão respiratória aguda, 3\% com lesão renal aguda, $4 \%$ com choque séptico e $1 \%$ com pneumonia e necessidade de ventilação mecânica. Em alguns casos graves houve infecção secundária por bactérias e fungos (cepas de Acinetobacter baumanni, Klebsiella pneumoniae, Candida albicans, etc). Concluem que é uma doença altamente contagiosa, principalmente onde há aglomerações, idosos e pessoas com comorbidades podem ter agravamento dos sintomas e morte.

\section{Antissepsia - Prevenção}

As estratégias imediatas de controle da transmissão do vírus são urgentes e necessárias, principalmente para pacientes com portadores de comorbidades e idosos. A transmissão de pessoa a pessoa pode ser maior nos hospitais, local onde a precaução com a geração de aerossóis é fundamental, por exemplo nos respiradores. Os impactos podem ser imensos no sistema de saúde de cada país e também na economia (PAULES et al., 2020).

As pessoas com maior risco de infecção são aquelas que estão em contato próximo com um paciente COVID-19 ou que cuida do mesmo. Nessa perspectiva tais medidas de prevenção se destacam: a higienização das mãos, com frequência, com água e sabão por pelo menos 30 segundos, e/ou a utilização do álcool etílico líquido ou em gel a 70\%; evitar tocar nos olhos, nariz e boca; tossir ou espirrar no cotovelo ou tecido dobrado ou lenços descartáveis e depois eliminar imediatamente; usar uma máscara descartável se tiver problemas respiratórios ou sintomas e realizar a higienização das mãos após descarte da máscara e a manutenção da distância social de no mínimo 1 metro. Os equipamentos de proteção individual na atenção primária, o uso de máscaras, luvas e avental de mangas longas é fundamental, bem como a desinfecção do ambiente após o atendimento (WHO b, 2020). A antissepsia, principalmente das mãos, é fundamental para evitar a proliferação de microrganismos capazes de desenvolver patologias.

Em um estudo que utilizaram aerossóis, plástico, papelão, cobre e aço contaminados com SARS-CoV-2 e SARS-CoV-1, usando um método 
Bayesiano, modelo de regressão, ficou demonstrado que o SARS-CoV-2 permaneceu viável em aerossóis durante toda a experiência (3 horas), com uma redução no título infeccioso. Essa redução foi semelhante à observada com SARS-CoV-1. Os materiais que apresentaram maior viabilidade do vírus foram o plástico e o aço inoxidável, em torno de 72 horas, no cobre nenhum SARS-CoV-2 viável foi detectado após 4 horas e nenhum SARS-CoV-1 viável foi detectado após 8 horas. No papelão, nenhum SARS-CoV-2 viável foi detectado após 24 horas e nenhum SARSCoV-1 viável foi detectado após 8 horas (DOREMALEN et al. 2020). Esse estudo reforça a importância de utilizar protocolos padrão na desinfecção de objetos inanimados, no procedimento adequado, no uso de EPIs e na escolha do desinfetante adequado.

$\mathrm{O}$ vírus se mostrou altamente contagioso, principalmente nos hospitais, e para minimizar as transmissões para os profissionais de saúde é importante considerar o uso da telemedicina para avaliar suspeita casos de COVID-19, a utilização de barreiras físicas como janelas de vidro ou plástico, máscara N95, avental de manga longa, óculos de proteção, touca, protetor facial de plástico, protetores de acrílico, capote impermeável, são medidas que reduzem a exposição ao vírus (HUANG et al., 2020; WHO b, 2020).

\section{Isolamento social}

Uma forma preventiva importante é a chamada quarentena. No mundo os governos estão impondo isolamento social, proibição de viagens, fechamento de fronteiras, proibição da entrada de estrangeiros de países fortemente afetados, mas, mesmo assim, as mortes ainda acontecem. Diante do exposto, e apesar de serem ferramentas utilizadas há muitos anos, é fundamental a discussão e a utilização de critérios técnicos de como proceder em caso de doenças altamente infecciosas. Os governos decretam o isolamento de pacientes suspeitos, o fechamento de ambientes não essenciais, no entanto $o$ não cumprimento pelas partes prejudicam as medidas preventivas, podendo incorrer em aumento de casos comunitários (WENDY et al., 2020).

A recomendação é que qualquer pessoa com os sintomas de COVID-19 deve permanecer em casa por 14 dias de forma isolada, sem receber visitas, a partir de quando os sintomas apareceram pela primeira vez, assim como todos os assintomáticos na casa em que mora, (BRASIL, 2020). Em caso de atendimento em algum ambiente de saúde é importante ter uma sala apropriada para o atendimento isolado, que possua janelas, com ar condicionado desligado, banheiros isolados e mobiliário não macio (RAZAY et al., 2020).

O momento é de reduzir o adoecimento de pessoas, fazendo com que haja menor número de casos severos que necessitem de internações e demandem recursos mais complexos de saúde, como internação em UTI e necessidade de assistência ventilatória, recursos que são desproporcionalmente disponíveis no sistema de saúde e que uma alta demanda levaria à sobrecarga desde sistema, como visto em países que tem um maior número de casos. É o que tem sido chamado de achatamento da curva de crescimento, que associado a medidas de informação a pacientes para prevenção do contágio e isolamento domiciliar de casos com sintomas leves seriam práticas que ajudariam o sistema de saúde a não entrar em colapso.

Um dos grupos mais respeitados em estudos epidemiológicos, a equipe de especialistas do Imperial College of London foi responsável pela mudança da estratégia adotada no Reino Unido, que, como alguns outros países, adotaram a estratégia de deixar manifestar a "imunidade de massa", que consistiria em não adotar medidas restritivas, possibilitando que o 
vírus infectasse a população e permitisse que rapidamente as pessoas pudessem ficar imunizadas. Este grupo de especialistas apresentou estudos em que projetava diversos cenários da epidemia para o Reino Unido e Estados Unidos, com base em dados de contágio, hospitalização, óbitos vistos em outros países e outros fatores, estudaram como o vírus se dissemina em diferentes ambientes, elaborando a projeção de casos conforme a estratégia adotada em cada cenário. Na previsão mais pessimista, com a livre circulação do vírus, haveria a infecção de cerca de $80 \%$ da população geral em um período muito curto e dos infectados $20 \%$ precisariam de hospitalização, $5 \%$ seriam críticos e precisariam de UTI com suporte respiratório, e cerca de metade dos casos críticos evoluiriam para o óbito (WALKER et al., 2020). Para esses autores, se a estratégia de supressão é adotada precocemente, ao atingir 0,2 óbitos/semana/100.000 habitantes, e sustentada, 38,7 milhões de vidas no mundo poderiam ser salvas, enquanto, se adotada quando ocorrer uma taxa de mortalidade de 1,6 óbitos/semana/100.000 habitantes, apenas 30,7 milhões seriam salvas. Quanto maior o adiamento das medidas de supressão de transmissão com o isolamento social, piores os resultados e menos vidas salvas.

\section{Grupos de risco (Cormobidades) e complicações}

Tudo começou com vários casos de pneumonia viral de etiologia desconhecida que foram admitidos no hospital de Wuhan, em 29 de dezembro de 2019 (KANNAN et al., 2020). Um estudo realizado no Hospital Jinyintan, Wuhan - China com pacientes confirmados para COVID-19, demonstrou que os sintomas iniciais na admissão hospitalar foram febre e tosse, seguidos pela produção de escarro e fadiga, e linfocitopenia (40\%). As comorbidades mais comuns, para quem precisou de internação, foram hipertensão, seguida de diabetes e doença cardíaca coronária. O tempo médio de internação foi de 22 dias e de óbito de 18,5 dias. A sepse foi a complicação mais frequentemente observada, seguida de insuficiência respiratória, insuficiência cardíaca e choque séptico. As chances de morte hospitalar foram maiores em pacientes com diabetes ou doença coronariana. A idade, linfopenia, leucocitose e ALT elevado, lactato desidrogenase, troponina I cardíaca de alta sensibilidade, creatina quinase, dímero $\mathrm{d}$, ferritina sérica, IL-6, tempo de protrombina, creatinina e procalcitonina também foram associados à morte (FEI et al., 2020).

Reconhecer até que ponto os surtos de doenças afetam mulheres e homens de maneira diferente é um passo fundamental para entender os efeitos primários e secundários de uma emergência de saúde. Dados apontam que morrem mais homens e talvez esteja relacionado ao tabagismo e diferenças imunológicas (WENHAN et al.,2020).

Em um estudo realizado na China em 575 hospitais, com 1590 pacientes com diagnóstico de COVID-19 laboratorialmente confirmada, os autores concluíram que o risco de desfechos adversos (admissão em unidade de terapia intensiva ou ventilação mecânica ou morte), foi maior pela presença de qualquer comorbidade, assim como piora com o maior número de comorbidades (GUAN et al., 2020). Neste estudo, as comorbidades foram auto relatadas na admissão e $25,1 \%$ dos pacientes apresentaram pelo menos uma comorbidade, sendo a mais prevalente a hipertensão arterial (16,9\%), seguida por diabetes $(8,2 \%)$, estando presentes ainda outras doenças cardiovasculares, e , em menor número, hepatite $\mathrm{B}$, doença pulmonar obstrutiva crônica, neoplasias e imunodeficiências. Também 8,2\% desses pacientes apresentaram duas ou mais comorbidades. Com a média de idade de 48,9 anos, a maioria de 
homens $(57,3 \%)$, com casos severos em $16.0 \%$ da população estudada. Após correção para idade e tabagismo, o risco relativo (RR) para atingir um desfecho foi de 2,68 para DPOC, 1,59 para diabetes, 1,58 para hipertensão e 3,5 para neoplasias malignas comparando com os pacientes sem comorbidades. $\mathrm{O}$ RR foi de 1,79 entre os pacientes com pelo menos uma comorbidade e RR de 2,59 se duas ou mais comorbidades.

\section{Impactos na saúde}

O impacto da saúde ocorre de forma avassaladora no contexto de uma pandemia. O mundo mostra cidades, regiões e países alterando completamente as suas rotinas pelo impacto causado pela infecção do SARS-CoV-2 por onde passa. Mais do que isso, por onde passa a pandemia evidencia a insuficiência nos estoques de insumos básicos de equipamentos de proteção individual (EPI), de testes diagnósticos, de equipamentos e da estrutura instalada para atendimento de pacientes atingidos. Soluções são procuradas para se evitar o colapso do sistema de assistência, com aquisição dos produtos necessários em um contexto de aumento extremo de demanda, levando à construção de hospitais de campanha para milhares de atendimentos, aquisições de equipamentos como os ventiladores para suporte em UTI's, leitos para hospitais, testes e insumos para realizá-los. Esta realidade se apresentou na China, Itália, Espanha e, agora, nos Estados Unidos. Situação crítica que leva à sobrecarga extrema dos profissionais de saúde, que muitas vezes tem que tomar decisões muito difíceis. Esta situação levou a Sociedade Italiana de Anestesia, Analgesia, Reanimação e Terapia Intensiva a emitir um documento sobre a admissão de pessoas em UTI nas condições excepcionais de desequilíbrio entre necessidades e recursos disponíveis, em eventos de emergência que obrigam os médicos a focar sua atenção na adequação do tratamento para aqueles que podem se beneficiar mais quando os recursos não são suficientes para todos os pacientes, e recomenda que aqueles com maior expectativa de vida sejam privilegiados (SIAARTI, 2020).

Para o Brasil, o sistema de saúde não comportaria um rápido aumento dos casos graves de COVID-19, segundo simulações realizadas pela UFMG e IPEA, considerando 437 microrregiões de saúde brasileiras, excluindo o Distrito Federal por suas peculiares características político-administrativo e socioeconômica (NORONHA et al, 2020). Foram considerados cenários definidos com base em diferentes taxas de infecção de $0,01 \%, 0.1 \%, 1 \%, 10 \%$, $20 \%$ e $40 \%$ (casos confirmados) e horizontes de propagação do COVID-19: curto prazo (1, 3, 6 meses) e médio prazo (6 e 12 meses). Em um mês (até o fim de abril), considerando o melhor cenário, com $0,1 \%$ da população infectada, já haveria sobrecarga dos leitos UTI em algumas microrregiões de saúde do Brasil. Se o percentual considerado for, em cada microrregião, $1 \%$ em um mês, o sistema entraria em colapso, com $53 \%$ das microrregiões de saúde operando além de sua capacidade.

Nas projeções para o Brasil, da equipe de especialistas do Imperial College of London, já citados acima, publicadas no dia 26/03/2020, no cenário 1 , sem medidas de mitigação, para a população total de 212.559.409, haveria uma população infectada de 187.799.806, com 1.152.283 mortes, 6.206.514 hospitalizações das quais 1.527 .536 em UTI. Com cenário em que são adotadas medidas distanciamento social de toda a população haveria redução para 627.047 mortes, 3.496 .359 hospitalizações e 831.381 internações em UTI. Haveria uma maior redução ainda se houver, além do distanciamento social, um reforço no distanciamento dos idosos, com 529.779 mortes, 3.222.096 internações e 702.497 leitos de UTI. As 
expectativas são piores se houver a adoção tardia de tais medidas supressivas (WALKER et al, 2020).

Os autores deste estudo observam que modelaram essas curvas com base nos padrões de dispersão dos países ricos e que nos países pobres os resultados da pandemia podem ser piores do que o previsto, sem levar em conta situações de falta de estrutura urbana que ocorrem em favelas, assentamentos, aglomerados de população e comunidades sem abastecimento de água e/ou saneamento, acesso a recursos de saúde e outras situações comuns no Brasil.

\section{CONCLUSÃO}

O SARS-CoV-2 é altamente contagioso, traz complicações sintomáticas para pessoas com comorbidades e idosos, sendo assim as estratégias para contenção do vírus são fundamentais para reduzir mortes, achatar a curva de crescimento e evitar o colapso do sistema de saúde. É o momento de atuação na divulgação de conhecimento em saúde para a população, para que a pandemia que chega ao país seja mitigada, preservando milhares de vidas com atitudes individuais. Fica também evidente a necessidade de estruturação do sistema de saúde para o enfrentamento de desastres, mesmo os provocados por agentes microscópicos, como o que se está enfrentando neste momento.

Este estudo corrobora como instrumento para o desenvolvimento de ações de conscientização e prevenção da COVID-19 e reforça a necessidade de mais estudos.

\section{AGRADECIMENTO}

Agradecemos à Universidade Federal do Tocantins e à Universidade Federal de Catalão.
Todos os autores declararam não haver qualquer potencial conflito de interesses referente a este artigo.

\section{REFERÊNCIAS}

ALHAZZANI, W.; MØLLER, M.H.; ARABI, Y.M.; LOEB, M.; GONG, M.N.; FAN, E.; OCZKOXISK, S.; LEVY, M.M.; DERDY, L.; DZIERBA A.; DU B.; ABOODI $M$. et al. Surviving Sepsis Campaign: Guidelines on the Management of Critically Ill Adults with Coronavirus Disease 2019 (COVID-19). SSC COVID-19 Guidelines Supplement (online) Acesso em 25 de março de 2020. Disponível em https://www.sccm.org/getattachment/Disaster/SSCCOVID19-Critical-Care-Guidelines.pdf?lang=en-US.

ARAÚJO-FILHO, J. A. B.; SAWAMURA, M. V. Y.; COSTA, A. N.; CERRI, G. G. E. NOMURA, C. H. Pneumonia por COVID-19: qual o papel da imagem no diagnóstico? J. Bras. Pneumol. 2020;46(2):e20200114. Disponível em https://dx.doi.org/10.36416/1806-3756/e20200114 . Acesso em 25 de março de 2020.

ARSHAD, A.S.; BALOCH, M.; AHMED, N.; ARSHAD A.A.; IGBAL, A. The outbreak of Coronavirus Disease 2019 (COVID-19)-An emerging global health threat., J. Infect. Public. Health. Mar 18, 2020. Doi: 10.1016/j.jiph.2020.02.033.

BATISTA A.; ANTUNES B.; FAVERET G.; PERES I.; MARCHESI J.; DANTAS L.; BASTOS L.; AGUILAR S.; RANZANI O.; BAIÃO F.; MAÇAIRA P.; HAMACHER S.; CARNEVALE R.; BOZZA F. Nota Técnica 4 - 21/03/2020 - NOIS (Núcleo de Operações e Inteligência em Saúde). - Projeção de casos de infecção por COVID-19 no Brasil até 30 de março. Inteligência computacional aplicada à predição da evolução da COVID-19 e ao dimensionamento de recursos hospitalares. Acesso em 28 de março de 2020. https://sites.google.com/view/noispucrio/publica\%C3\%A7\%C3\%B5es?authuser=0\#h.ni iouup8rvuu

BLACK JG. Microbiologia - Fundamentos e Perspectivas. 4 ed. Guanabara Koogan. 2002.

BRASIL. Portaria No 356, 11 de março de 2020. Órgão: Ministério da Saúde/Gabinete do Ministro. CABRERA, S.F.D.; CLAVEL, L.L.M.; ROMÁN, L.A.H. COVID-19. Visión del Anestesiólogo. Rev. Cuban Cardiol. V. 26, n. 1, p. 1-5, 2020.

CHEN, N.; ZHOU, M.; DONG, X.; QU, J.; GONG, F.; HAN, Y.; QIU, Y.; WANG, J.; LIU, Y.; WEI, Y.; 
XIA, J.; YU, T.; ZHANG, X.; ZHANG, L. Epidemiological and clinical characteristics of 99 cases of 2019 novel coronavirus pneumonia in Wuhan, China: a descriptive study. The Lancet. v.395, n.15, 2020.

Diário Oficial da União. Edição: 49 | Seção: 1| Página: 185. Publicado em: 12/03/2020.

DOREMALEN, N.V.; MORRYS D.H.; HOLBROOK, M.G.; GAMBLE A.; WILLIAMSON, B.N.; TAMIN A.; WILLIAMSON, J.L.; THORNBURG, N.J.; GERBER, S.I.; LLOYDSMITH, J.O.; WIT, E.; MUNSTER, V.J. Aerosol and Surface Stability of SARS-CoV-2 as Compared with SARS-CoV-1. The New England Journal of Medicine. March 17, 2020. Downloaded from nejm.org on March 20, 2020.

ECEMIS, T.; YILMAZ, O.; SANLIDAG，T. ; AKCALI, S.; YUKSEL, H. Investigation of viral agents by multiplex PCR in children with symptoms of upper respiratory tract infection. Journal of Dr. Behcet Uz Children's Hospital, v. 2, n.1, p. 1-5, 2012.

FEI, Z.; TING, Y.; RONGHUI, D.; GUOHUI, F.; YING, L.; ZHIBO, L.; JIE, X.; YEMING, W.; BIN, S.; XIAOYING, G.; LULU, G.; YUAN, W.; HUI, L.; XUDONG W.; JIUYANG, X.; SHENGJIN, T.; YI, Z.; HUA, C.; BIN, C. Clinical course and risk factors for mortality of adult inpatients with COVID-19 in Wuhan, China: a retrospective cohort study. The Lancet. V.395, March 18, 2020.

GUAN W.; LIANG W.; ZHAO Y.; LIANG, H.; CHEN, Z.; LI, Y.; LIU, X.; CHEN, R.; TANG, C.; WANG, T. et al. Comorbidity and its impact on 1590 patients with COVID-19 in China: A Nationwide Analysis. Eur. Respir. J. Acesso em 27 de março de $2020 . \quad$ Disponível em: https://doi.org/10.1183/13993003.00547-2020.

HUANG, C.Y.; WANG, X.; LI, L.; REN, J.; ZHAO, Y.; HU, L.; ZHANG, G.; FAN, J.; XU, X.; GU, Z, et al. Cheng. Clinical features of patients infected with 2019 novel coronavirus in Wuhan, China. The Lancet, v. 395, n. 10223, pp. 497-506, 2020. Doi: https://doi.org/10.1016/S0140-6736(20)30183-5.

JONES, D.S. History in a Crisis - Lessons for COVID-19. N. EngL. J. Med. March 12, 2020.

KANNAN, S.; ALI, S.P.S.; SHEEZA, A.; HEMALATHA, K. COVID-19 (Novel Coronavirus 2019) - recent trends. European Review for Medical and Pharmacological Sciences. Eur Rev Med Pharmacol Sci; v.24, n.4, p. 2006-2011, 2020.
KASMI, Y.; KHATABY, K.; SOURI, A.; ENNAJI, $M$. Coronaviridae: 100,000 Years of Emergence and Reemergence. Emerging and Reemerging Viral Pathogens. Chapter 7, Elservier, vol. 1, Pages 127-149, 2020.

LAN, L.; MD, XU, D.; YE, G.; XIA, C.; WANG, S.; LI Y.; XU, H. Positive RT-PCR Test Results in Patients Recovered From COVID-19. JAMA, February 27, 2020.

LI, F. Receptor recognition and cross-species infections of SARS coronavirus. Antiviral Research, v. 100, Issue 1, October 2013, Pages 246-254.

LI, R.; PEI, S.; CHEN, B.; SONG, Y.; Tao ZANG, T.; YANG, W.; SHAMAN, J. Substantial undocumented infection facilitates the rapid dissemination of novel coronavirus (SARS-CoV2). Science, 16 Mar, 2020.

NG OT; MARIMUTHU, K.; CHIA, P.Y.; KO, V.; CHIEW, C.J.; WANG, L.; YOUNG, B.E.; CAHN, M.; VASOO, S.; LING, L.M.; et al. SARS-CoV-2 Infection among travelers returning from Wuhan, China. N. Engl. J. Med. 2020 Mar 12. doi: 10.1056/NEJMc2003100.

NICOLINI, A.; CLAUDIO, S.; RAO, F.; FERRERA, L.; ISETTA, M.; BONFIGLIO, M. Pneumonia associada a influenza A (H1N1). J. Bras. Pneumol., São Paulo, v. 37, n. 5, p. 621-627, Oct. 2011.

NORONHA, K.; GUEDES, G. R.; TURRA, C. M.; ANDRADE, M. V.; BOTEGA, L.; NOGUEIRA, D.; CALAZANS, J.; CARVALHO, L.; SERVO, L.; AMARAL, P. Análise de demanda e oferta de leitos hospitalares gerais, UTI e equipamentos de ventilação assistida no Brasil em função da pandemia do COVID19: impactos microrregionais ponderados pelos diferenciais de estrutura etária, perfil etário de infecção e risco etário de internação. Nota Técnica $n^{0} 1$. CEDEPLAR/UFMG: Belo Horizonte, 2020. (online). Acesso em 28 de março de 2020. Disponível em: $\quad$ https://geesc.cedeplar.ufmg.br/wpcontent/uploads/2020/03/Nota-tecnica-final-COVID19-revisado2.pdf.

PAULES, C.I.; MARSTON, H.D.; FAUCI, A.S. Coronavirus Infections-More Than Just the Common Cold. JAMA, February 25, v. 323, n. 8, 2020.

RAZAI, M.S.; DOERHOLT, K.; LADHANI，S.; OAKESHOTT, P. Coronavirus disease 2019 (COVID-19): a guide for UK GPs. BMJ, v. 368, m800. doi: https://doi.org/10.1136/bmj.m800. 
SIAARTI - Sociedade Italiana de Anestesia, Analgesia, Reanimação e Terapia Intensiva. Clinical Ethics Recommendations for the Allocation of Intensive Care Treatments in exceptional, resource-limited circumstances - Version n. 1. Posted on March, 16th - 2020. Acesso em 28 de março de 2020. Disponível em http://www.siaarti.it/SiteAssets/News/COVID19\%20 -\%20documenti\%20SIAARTI/SIAARTI\%20$\% 20$ COVID-19\%20\%20Clinical\%20Ethics\%20Reccomendations.pdf

SOCIEDADE BRASILEIRA DE ANÁLISES CLÍNICAS (SBAC). COVID-19. Disponível em: http://www.sbac.org.br/blog/2020/03/25/metodoslaboratoriais-para-diagnostico-da-COVID-19/.

Acessado em 30/03/2012.

VALENTÍN E.D.L.; MONTERO J.S.N.; FLORENTINI, M.G.Q. Coronavirus causante del síndrome respiratorio de Oriente Medio (MERSCoV). Revista Médica Carriónica, v.1, n. 1: I, 2019.

VICENZI, E.; CANDUCCI, F.; PINNA, D.; MANCINI, N.; CARLETTI, S.; LAZZARIN, A.; BORDIGNON, C.; POLI, G.; CLEMENTI, M. Coronaviridae and SARS-associated Coronavirus Strain HSR1. Emerg. Infect. Dis., Mar; v. 10, n.3, p. 413-418, 2004. doi: 10.3201/eid1003.030683.

WALKER, P.G.T; WHITTAKER, C.; WATSON, O.; BAGUELIN,M.; AINSLIE, H.E.C.; BHATIA, S.; BHATT, S.; BOONYASIRI, A.; BOYD, O.; CATTARINO, L.; et al. The Global Impact of COVID-19 and Strategies for Mitigation and Suppression. Abdul Latif Jameel Institute for Disease and Emergency Analytics, Imperial College (online). Acesso em 28 de março de 2020. Disponível em:
college/medicine/sph/ide/gida-fellowships/ImperialCollege-COVID19-Global-Impact-26-03-2020.pdf

WENDY, E.; PARMET, J.D.; SINHA, M.S. COVID19 - The Law and Limits of Quarantine. New England Journal of Medicine, march 18, 2020. doi: 10.1056/NEJMp2004211.

WENHAN, C.; SMITH, J.; MORGAN R. COVID-19: the gendered impacts of the outbreak. The Lancet, v. 395, n. 10227, p. 846-848, 2020.

WHO a. Coronavirus Disease 2019 (COVID-19): Situation Report-51. Publicado em 11 de março de 2020. Disponível em: https://www.who.int/docs/defaultsource/coronaviruse/situation-reports/20200311sitrep-51-COVID-19.pdf. Acesso em 27 de março de 2020.

WHO b. Rational use of personal protective equipment for coronavirus disease 2019 (COVID19). Interim guidance, 27 February, 2020. Disponível em:https://apps.who.int/iris/bitstream/handle/10665/3 31215/WHO-2019-nCov-IPCPPE_use-2020.1eng.pdf?sequence $=1 \&$ isAllowed=y. Acesso em 27 de março de 20

WONG, H. Y. F.; HIU YIN SONIA LAM, AMBROSE HO-TUNG FONG, SIU TING LEUNG, THOMAS WING-YAN CHIN, CHRISTINE SHING YEN LO, MACY MEI-SZE LUI, JONAN CHUN YIN LEE, KEITH WAN-HANG CHIU, TOM CHUNG, ELAINE YUEN PHIN LEE, ERIC YUK FAI WAN, FAN NGAI IVAN HUNG, TINA POY WING LAM, MICHAEL KUO, MING-YEN NG. Frequency and Distribution of Chest Radiographic Findings in COVID-19 Positive Patients. Radiology. 2019 Mar 27 [Online ahead of print]. Acesso em 28 de março de 2020. Disponível em https://doi.org/10.1148/radiol.2020201160 